\title{
On Composition Devices in Modernist Architecture: The Case of De Vore House and House II
}

\author{
Michael Jasper \\ Faculty of Arts and Design, Discipline of Design and Architecture, University of Canberra, Canberra ACT 2601, Australia
}

\begin{abstract}
This paper examines general composition problems in modernist architecture by means of a close analysis of the formal principles and devices at work in two exemplary mid twentieth century projects, De Vore House by Louis Kahn (1901-1974) and House II by Peter Eisenman (1932). The goal of the paper is to inaugurate a larger research project into the design processes and spatial-formal effect at work in modernist architecture. The methodology is primarily visual, and postulates a range of form relationships for the creation and interpretation of works of architecture. Following an introduction to the research problem, an analysis of the case study projects is undertaken according to three themes: plan disposition, ambiguity in wall and column relations, and volume as impacting on movement. A concluding section summarizes the findings and suggests future lines of research. The paper's significance lays in its contributions to discussions around architectural practice at a specific moment in modernist architecture's mid twentieth century trajectory, to our understanding of a number of formal strategies and their resulting architectural effects, and to scholarship on the practice and theories of Kahn and Eisenman.
\end{abstract}

Key words: Composition, column, ground, modernist architecture, plan disposition.

\section{Introduction}

This paper initiates a research project into architectural composition generally and modernist architecture's design processes specifically. It works on elements, mechanisms, and spatial effects. The project initially will focus on a limited number of such compositional elements and devices. Three generic design problems are taken as a starting point and subsequent efforts will refine, expand, and adjust the terms of reference and the range and type of test case. The three problems or rubrics concern plan disposition, oscillating wall and column relationships, and the capture or release of movement. Each of these rubrics is offered as one aspect of compositional processes rendered in works of modernist architecture. The order is relative and all three can be said to converge in a unique space sensation or space conception. Each could serve as the theme of a particular sequence in design research in architecture.

Corresponding author: Michael Jasper, Ph.D., research fields: modernist form, contemporary thought and the art of city design. E-mail: michael.jasper@canberra.edu.au.
For this initial foray, two houses provide the material for the research, De Vore House by Louis Kahn (1901-1974) and House II by Peter Eisenman (1932). Kahn was commissioned in 1954 to design the Weber De Vore House for a site outside of Philadelphia in Springfield Township. Kahn published a diagrammatic plan and sketch elevation, along with a brief text on the unbuilt house in 1955. Secondary writings have tended to focus on the place this house has within the trajectory of his work [1-5].

Eisenman's House II was designed for an academic couple on a gently sloping 100-acre, roughly 40-ha, site in Vermont and completed in 1969. It was the topic of an extended meta narrative by Eisenman in "Five Architects”. A number of preparatory sketches, analytic diagrams, conceptual models, and photographs were reproduced in "Houses of Cards", and brief descriptions can be found in monographs on his work [6-9].

I will discuss the two projects largely from a formal point of view. As first published, both insist on formal appraisal. One might suppose House II to more 
immediately call for such a position when compared to De Vore, but as the analysis shows, De Vore House equally calls for such a viewpoint. The two projects provide an appropriate set of case studies for comparative interrogation of composition in the realm of architecture. Of similar scale, rendering diverse conditions, they sit within a lineage of experimental work in small residential projects and, though unbuilt, each has proven influential to both practice and theory.

The paper sets out a preliminary approach to investigating the nature of certain design principles and a limited number of architectural form relationships including compression (or collapse), dispersal (or distancing whether in a linear or a centroidal or a pinwheel motion), and diagonality (or rotation). The paper contributes to discussions around practice at a formative moment in architecture's trajectory, adds to our understanding of possible formal strategies and architectural effects, and makes a contribution to scholarship on Kahn and Eisenman. It is part of a larger work in progress on mid 20th century tendencies in practice and historiography and is an experimental work on design research in architecture.

A number of propositions organize the larger project and establish one context for the current paper. The first proposition concerns architectural form and claims that the range of spatial and temporal effects in a work of architecture resulting from specific combinations of elements and relations is at any one moment limited. It suggests that various spatial systems or styles have their own combinations. Such a point of view, for example, can be found in that neo-“classicist” style that Rowe (1920-1999) [10] discovered around the same period.

The second proposition concerns methodologies of design research and claims that studio or form-based research, as compared to traditional text-based methods, has a more plastic and intimate relation to the work. The process of research thus has an interpretive as well as an explicitly creative side.

A correlative proposition is that there are a limited number of space systems, analytic methods, and stylistic strategies to deploy when describing works of modern architecture. It is proposed that they result, and differentiate themselves one from the other, in the manner by which they reappraise the forms and functions attributed to key architectural elements. For the purposes of this paper, and claiming value in a preliminary look, I briefly touch on column, wall, and volume and their conjunction around ideas of structure (frame, bay, skeleton) and spatial animation. Other categories should also be turned to in subsequent studies for describing overall distribution and these might equally or more accurately be identical to the material under review.

Turning now to the analysis of the select projects, it is worth recalling the three organizing themes. The first concerns plan disposition and, in part, ground relationships. Which kinds of organizational form and idea characterize the overall functioning of the two plans? What are the differences? Column/wall oscillations are evident in both projects. This is explicit in the case of House II, more allusive in De Vore. In Eisenman's project, the column/post undergoes transformations in orientation and integration with planes. In De Vore, multiple column/pier to wall transformations are occur. How might the differences be characterized? Movement, resulting in part from volume distribution, is the third theme. In House II, sectional relations emphatically record an echelon or spiral. The plan reveals a similar movement in De Vore. Both projects rely on slots to transition between slipping, major volumes. Or are the slots, whether in section or plan, in reality not gaps between but in fact elisions or cuts within a larger figure? Are the effects or consequences different and, if so, what are the distinguishing spatial characteristics?

\section{Analysis}

To being this section, I start with a citation from Kahn about De Vore House, a characteristically allusive and evocative statement on the relation of the 
plan to space. Kahn [1] writes: "In searching for the nature of spaces of house, might they not be separated a distance from each other theoretically before they are brought together. A predetermined total form might inhibit what the various spaces want to be.... The order of construction should suggest an even greater variety or design ... and more versatility”.

\subsection{Plan Dispositions}

First published by Kahn in 1955, the plan diagram renders the location and relative size of existing trees on the site and a potential contrapuntal relation with piers of the future house.

De Vore House suggests an exploration into architectural-tectonic structure as a series of spatial units, or spatio-structural units as the main ordering element. In Fig. 1, Kahn [1] who accompanied De Vore's original publication, characterizes his general intent as one of spacing or distancing. It results in a plan form he calls a cluster. As will be seen later in relation to House II, the idea of the cluster or aggregate is shared between the two projects. This is briefly suggested by Brownlee and de Long [4].

The first thing one notices in the published diagram is that there is no center. Or if there is a center, it has taken on the form of a line. Perhaps the edge of the retaining wall is the center. The various spaces could then be described according to specific wall/edge relationships. The outdoor court and garage units are fully detached, the others slipping.

The absent center, to take another starting point, perhaps justifies considering the plan as a modification of a four-square plan. Fig. 2 diagrams possible variations or mutations in De Vore on the ideal four-square plan.

The four-square plan has a point, or a cross, at its center. Kahn takes the ideal of 26 foot $(8 \mathrm{~m})$ spatio-structural unit and, perhaps partly in response to site conditions including existing trees and a steep change in topography, places the house on top of a ridge or proposed retaining wall. The center can be said

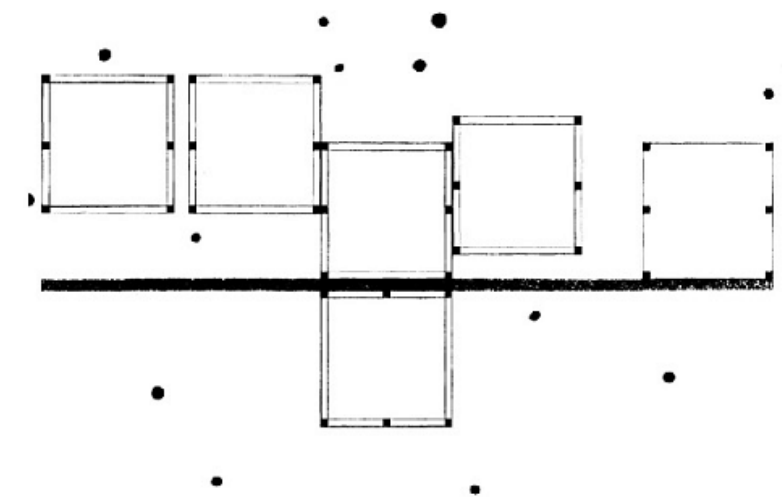

Fig. 1 De Vore House, plan diagram, Louis I. Kahn, 1955 (Louis I. Kahn collection, The University of Pennsylvania and the Pennsylvania Historical and Museum Commission).

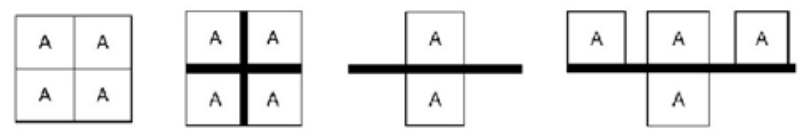

Fig. 2 Four-square variations in De Vore House.

to have shifted from a point to a line or wall. And the other spatial units are given distance, freed from the grip of the single point or cross, and drift or disperse, slipping one from the other, attracted or repelled. A gap or a gapping relation is realized between units, with that infamous wall or horizon line or edge inserted between.

The plan for De Vore as initially published is composed of six units in a group or cluster plan. Which kind of order is it? It has been characterized as composed of informally grouped pavilions. There is, however, a doubling of the column/posts in the six structural units. This introduces a direction in the otherwise supposedly neutral space, though it is hard to image any space being neutral when one begins to examine the subtle inflections that always accompany Kahn's work. In the first published plan, for example, the sixth unit to the lower side of the wall rotates $180^{\circ}$ to introduce a cross axial movement into the whole.

The figure of the main building form is ambiguous, not shaped into a pyramidal mass even with the extra height of the living room. The spatial or area units appear somewhat adrift, maybe even randomly placed, responding to no apparent single compositional order. To take an opinion of Peter Smithson (1923-2003) and 
Alison Smithson (1928-1993), there are traces of Blenheim here but differently expressed following a lead, they say, is announced but not expanded upon by Kahn [11]. And Kahn's observation about avoiding the constraints of that "pre-determined total form" finds expression. So how might we describe the order?

Perhaps De Vore House should be read as simply additive. It works to deflect any reading of centralization or hierarchy or part to whole relation. There is only a part-to-part logic at work, one different from, as will be seen, House II (Fig. 3).

Confronted with the plan, one might ask if House II functions within the parameters of typical composition formats? Is it critical of them, does it introduce new instruments or effects? Or is it the inflect old instruments and devices to create another kind of overall organization?

The first impression is that House II can be read as a transformation or simple variation on the nine-square plan: it suggests an erosion or a transcription, a subtle variation one consequence of which is that the center is displaced, bent into an el shape. Or perhaps it is more accurate to claim that the center is transformed into a permanently absent promise. A second interpretation is that background space, which normally might have resulted from plaiding, is moved to the perimeter and becomes figural. Or perhaps there are only figures of similar value and role and no ground, no background at all: everything is figure. All three alternatives could be tested.

The following suggests possible diagrams of the movements and transformations from a generic nine-square starting condition. In particular, potential shifts of the center should be noticed. The diagrams only suggest plan and not sectional moves, the latter to be considered later in this paper (Fig. 4).

Bands of space in the left and upper edges of the plan can be seen to not contribute to forming or shaping a space. House II can therefore be said to emphasize peripheral composition. This can be interpreted as an exploration into edge relations that further blur its

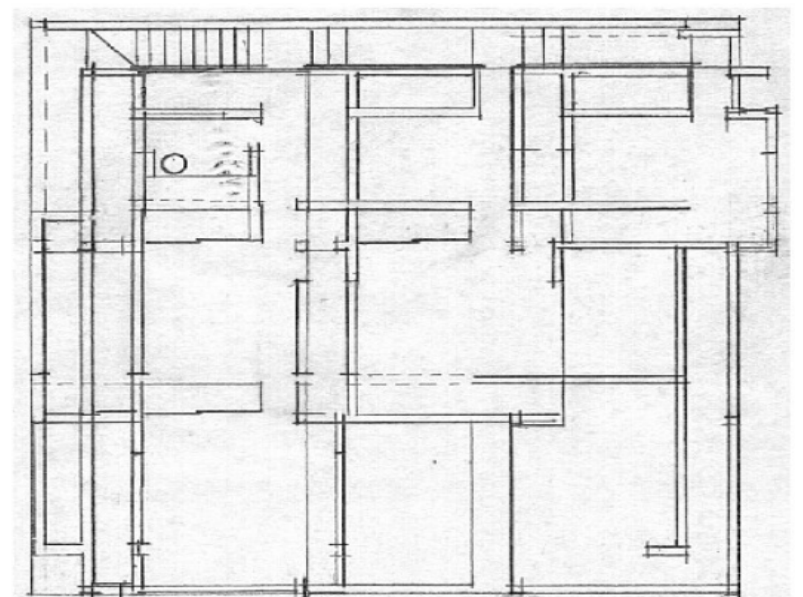

Fig. 3 House II, upper level plan, Peter Eisenman, 1969 (original drawing by the author after a drawing by Peter Eisenman).

\begin{tabular}{|l|l|l|}
\hline $\mathrm{A}$ & $\mathrm{B}$ & $\mathrm{A}$ \\
\hline $\mathrm{B}$ & $\mathrm{C}$ & $\mathrm{B}$ \\
\hline $\mathrm{A}$ & $\mathrm{B}$ & $\mathrm{A}$ \\
\hline
\end{tabular}

\begin{tabular}{|c|c|c|}
\hline$A$ & $B$ & $A$ \\
\hline$B$ & $A$ & $(B)$ \\
\hline$A$ & $(B)$ & $(C)$ \\
\hline
\end{tabular}

\begin{tabular}{|c|c|c|}
\hline$C$ & $B$ & $A$ \\
\hline$B$ & $A$ & $(B)$ \\
\hline$A$ & $(B)$ & $(A)$ \\
\hline
\end{tabular}

Fig. 4 Nine-square variations in House II: centers and els.

nine-square origin. In the upper left of the upper level plan, for instance, there is a stratification of the vertical elements, generally in a diagonal orientation, that work to reinforce this with the former center pushed either to the lower right or the upper left of the plan (Fig. 3).

Different from De Vore, there is more of a part to whole logic at work in the generation of the plan as described by Eisenmanand as illustrated in a series of 35 diagrams which reinforce this reading [8]. House II can be read, when compared to De Vore, as more stable, centralized, and balanced if one accepts a part to whole ambition. In a statement that accompanied the publication of House II in 1974, Eisenman [6] supports the interpretation of a totalizing aim in the design process, the goal he writes being to create a "total structure of relationships”.

\subsection{Oscillation}

Oscillating column and wall relationships emerges as the second theme from the analysis. Such oscillations are evident in both houses. Are they of the same nature or made manifest from the same devices? 
Are they more clearly worked on in elevation or in section? How might the differences be characterized?

Both projects contain evidence of ambiguities in column/wall readings and an engagement with the potential therein. These can range from a choice and use of different materials to decisions on the layout or finish of similar materials. At first glance, this is explicit in the case of House II, more allusive in the case of De Vore. In House II, the column/post undergoes transformations in its orientation and in its integration with wall planes. In De Vore House, multiple column/pier to wall variations are tested (Fig. 5).

In Kahn's language, there is a general intention to search for variety and versatility of expression [1]. In De Vore, devices include laying brick in a non-supporting manner in in-fill situations to differentiate them from bricks with a supporting role. There are three column/wall relations at work in De Vore House: co-planer, slipping and free. Co-planar or contiguous is the most common condition and occurs, for example, in the living room where the piers are on the same centre line as the cavity wall and glass. Evidence of slipping is seen in the relations of the third and fourth spatial units, counting from the left, with the fourth unit seeming to slide up or down in search of a good fit (Figs. 1 and 6). In a sketch plan, the free condition is seen, for example, in the two facing column-piers of units one and two, as well as in the suddenly loose middle bottom column of unit 3 (Fig. 6).

Which are the instruments of connection or dissolution between them? A preliminary review of the conditions reading left to right from the published elevation suggests the following: free standing pier; gap; pier to cavity wall or glass; rotated pier (see the different head or capital conditions in the projecting spatial unit); full height glass infill; pillar; void (neither spatial unit nor quite a full space in itself); pillar, cavity wall, pillar (the only pure condition in this elevation being that of the garage) (Fig. 6).

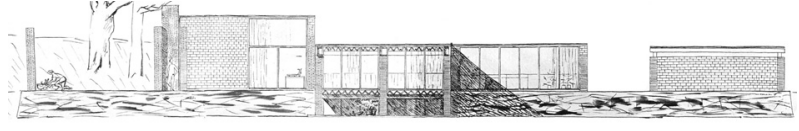

Fig. 5 De Vore House, elevation, Louis I. Kahn, 1955 (Louis I. Kahn Collection, The University of Pennsylvania and the Pennsylvania Historical and Museum Commission).

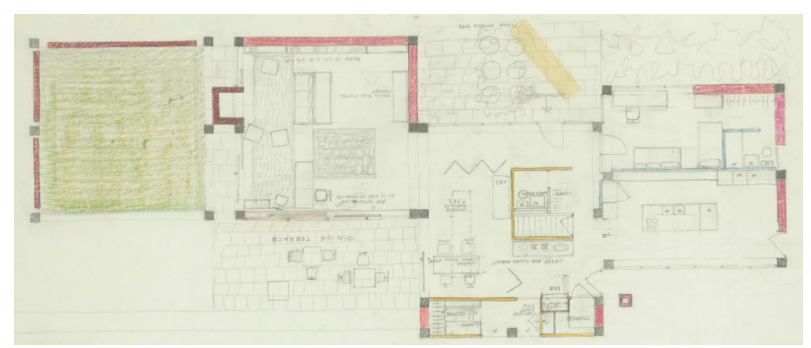

Fig. 6 De Vore House, partial sketch plan, Louis I. Kahn, 1955 (Louis I. Kahn collection, The University of Pennsylvania and the Pennsylvania Historical and Museum Commission).

One way to form the question of the column in House II is to ask at what moment, or under what conditions, does the vertical frame become a column, or the column part of a larger skeletal frame? It appears that the frame was there from the beginning and evolved toward, in only very limited instances, a column. In House II, it is in fact the column in question, or is it more precisely a matter of panel or pilaster to frame relations?

Another way to phrase the question of oscillations resulting from manipulation of columns and walls, or columns into wall: where does the wall become a plane or certain planes become elements of a larger structural frame? And these would be added the question of style: does the column's presence necessarily reveal a classical sentiment and the structural frame a modernist one? And what of that supposed mannerist tendency, that variation on a stable language? Can we identify mere characteristics as evidence of traditional architectural instruments, those such as the reveal, the partial reveal, the false capital, the plinth, the shadow line, the pilaster, in other words, that whole world of moldings?

It is perhaps in House II that a more literal transcription of a system of column, wall, roof or ceiling plane relationships is realised. De Vore is an 
immaculate translation of distinctions between functions of support and of enclosure. House II seems to not take these on, or perhaps more accurately takes them on in an empatically secondary and not primary manner. Support is assumed to be located in the skeleton frame so present as to constitute the thing itself, all else relegated to incident (Fig. 7).

Kahn's "thing itself", the spatiostructual unit, is neither bay, skeleton frame, nor free plan, and thus the function of the column/pier is singular, without easy precedent. The question about the role of the column and wall as variation on support/skin relationships requires reformulation. The order of the spatial unit (room, pavilion) in a free or open group plan versus the order of the skeleton frame could be an alternate formulation. Absent are the elements and relations that characterise international style space. It is perhaps an example of a free group plan: the collective plan which manifests a "this and this" or part and part relation suggested under the first rubric above.

To take it differently, the column or frame post of House II tends to emphatically function to mark a place in the larger frame or skeleton system, the column or structural pier in De Vore House to play the part in defining a major volume or unique spatical idea. The presumed neutrality of the latter, however, is agitated by the sequence of shifts of other spatiostructural units and as a consequence of the specific relation to whatever occupies the position of infill and in whatever manner (gap, align, transparent and opaque).

In House II, the column is tied to a network of walls, screens and beams that coalesce into a larger entity. The pier of De Vore is more autonomous, its identity unique and the walls, whether internal partitions, or serving as external enclosure, exist as mutations of a modern/international style logic of point support and screen that retain their autonomy. House II suggests a sensibility which favours the continuous (even ifcomplex and agitated) whole and De Vore House a sensibility which favours mutliple, separate entities.

\subsection{Volume Movement}

Movement, especially in the form of echeloned volume arrangements, is the third theme or rubric. In House II, sectional relations emphatically record an echelon or spiral (Fig. 8) and a certain reading of the plan reveals a similar movement in De Vore (Fig. 6). Both projects rely on slots to transition between slipping, major volumes. Or they are the slots, whether in section or plan, in reality not gaps between but in fact elisions or cuts within a larger figure? Are the effects or consequences different and, if so, what are the distinguishing spatial characteristics?

The trajectory created by the disposition of volumetric elements puts space in motion. In De Vore House, the following devices are at work: slipping, gaps, height differentials. The slippage of the two central volumes relative to the adjacent ones is a first design decision that puts the whole into motion. Departing from a static, simple linear or stepped push-pull relation, the slipping pushes the emphasis to the right. This is reinforced by the partial slipping of the fourth

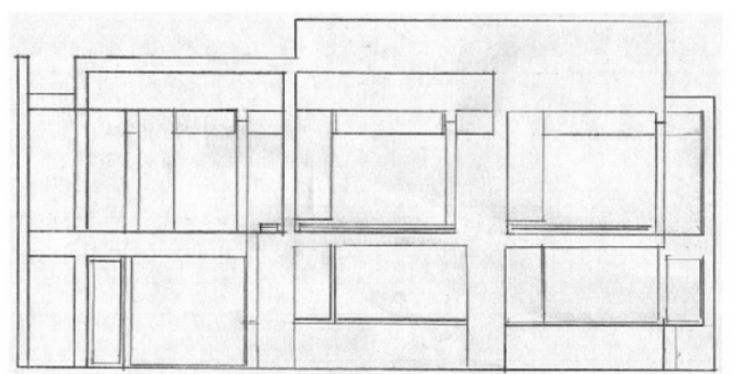

Fig. 7 House II, west elevation, Peter Eisenman, 1969 (original drawing by the author after a drawing by Peter Eisenman).

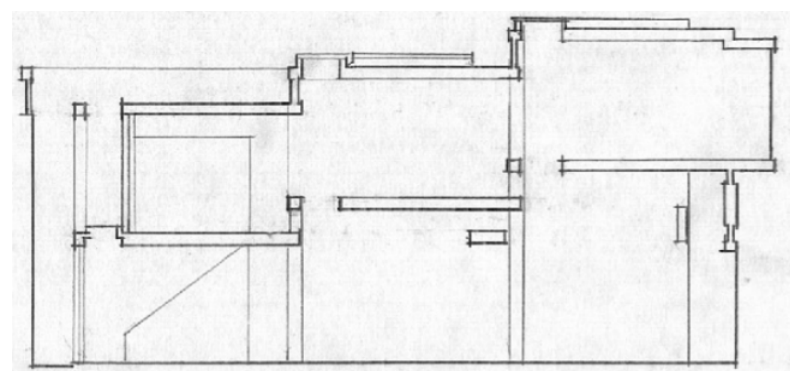

Fig. 8 House II, east-west section looking north, Peter Eisenman, 1969 (original drawing by the author after a drawing by Peter Eisenman). 
unit - counting the six units left to right and upper to lower units of the plan - to a not-quite quarter unit away from the upper alignment. This ensures that the house is not perceived as a central pavilion with flanking volumes. And further avoidance of a bi-lateral symmetric reading is completed with the detachment of the garage unit from the other five.

In certain instances, the units slip along a line. In other cases, the units pull apart and a gap is created. The effect of the gap depends in part on the specific situation as, for example, comparingthe case of the living room and courtyard units.

In House II, there is evidence of axial and cross-axial planning seen, for example, in the ground floor plan. In De Vore House, an other order is present, and perhaps the description by Brownlee and de Long [4] of an order of the cluster or pavilions is correct.

To take another measure, De Vore displays a general condition of frontalization established by the roughly symmetrical, and certainly balanced, distribution of the front five pavilions with entry on the middle all framed, in plan at least, by the heavy line of the wall. A play of frontalization and rotation is introduced through the increased height of the second unit and the drifting of the other units to the left and right or up and down relative to the wall. This play is further reinforced by a series of minor cross-axial moves which echelon or stagger along left to right or right to left depending on which is taken as the beginning element.

If the internal partitions in Kahn's sketch plan are emphasized, however, there is evidence of a centripetal force that resemble certain classic international style space episodes. Such a reading, if expanded, would focus on the internal pinwheel or fugal movement that results from the manner in which light or movement slips away at the corner of the glass or cavity wall.

In House II, structural and spatial expression are more or less integral, even allowing for the duplication of structural frames as claimed by Eisenman. De Vore House maintains, if we accept that the spatial experience is that primarily between things, an independence of the two. A review of changing ceiling articulations demonstrates the difference. House II emphatically reveals the frame, with beams tied to columns or to shear walls, even if there are all those mannerist inflections which complicate the real. The ceiling in De Vore House is more neutral, more bound to the individual spatiostructural cell to which it belongs and in this resolves or ignores the problems of frontality and centralization that occupy House II, which is not to imply a value to either, just a difference.

\section{Conclusions}

Table 1 sets out, provisionally and in one possible way, the approach and problems, the materials, and the preliminary findings revealed in the above analysis.

As a form of open-ended conclusion, the form relationships revealed in this brief analysis can be reviewed. Ambiguities in the two projects are manifest throughout. There is ambiguity in the overall plan distributions. The plans are additive and subtractive. Or more accurately, they are a record of erosion and expansion/growth, a case of collapse as well as a case of dispersal. De Vore is breaking apart, drifting out in a gentle, gradual centripetal way and at the same time

Table 1 Design problems, case studies and findings.

\begin{tabular}{|c|c|c|}
\hline Design conditions & De Vore House & House II \\
\hline Ground plan disposition & $\begin{array}{l}\text { Four-square modified } \\
\text { Ambiguous shape } \\
\text { Part to part relationship }\end{array}$ & $\begin{array}{l}\text { Nine-square variations } \\
\text { Single, clear volume } \\
\text { Part to whole relationships }\end{array}$ \\
\hline Column wall & $\begin{array}{l}\text { Pier to wall } \\
\text { Contiguous, contingent } \\
\text { Pier to cavity wall to glass }\end{array}$ & $\begin{array}{l}\text { Skeleton } \\
\text { Post/frame to pilaster to wall }\end{array}$ \\
\hline Volume movement & $\begin{array}{l}\text { No single centre: spacing } \\
\text { Slide or slip: echelon } \\
\text { Frontalization and rotation }\end{array}$ & $\begin{array}{l}\text { Perimeter emphasis } \\
\text { Linear and spiral } \\
\text { Contained }\end{array}$ \\
\hline
\end{tabular}


the spatial units are coalescing into a coherent shape. The four-square diagram is perhaps helpful in illustrating these simultaneous conditions. House II realizes an erosion from a pure state and at the same time it is an implosion, a multiplication or growth from a nine-square beginning, one diagonally expanding.

Another kind of ambiguity is available in the space system at work. Frampton sees, in Eisenman's contemporaneous House I, there is clear evidence of a picturesque-rationalist sensibility overlain on an analytically classical organization [6]. And Kahn's De Vore House might be said to create sensations both modern and primitive, perhaps a residue of that Greek revival in the air. So ambiguity of space conception broadly could be another way to describe the effect.

Frontalization and rotation, frontal and diagonal are additional themes. And there is an ambiguity of skin and structure readings in both. Only touched on here, but to be examined more in the future, it is the relation to site. House II is emphatically stereometric, a single mass (even if eroded or built up), sitting flat on the crest of its low hill. It does not yet begin to work the ground as certain of Eisenman's later projects, such as House X, will miraculously do. In terms of a response to site, in De Vore the ground relationship is ambiguous. It can be read as a hinged relation, one calling into question the role of the wall. Tilting over, the house is not quite balanced in the first published plan. In the sketch plan (Fig. 5), the house no longer appears to project over the wall, perching there, unresolved and tentative at this stage.

The initial analysis complete, are there generalizable lessons whether of substance or that of method? The three terms of reference-plan disposition, column to wall relations, movement-have had more or less success as tools for critical analysis. The beginning assumption that the building's ground relation would be revelatory proved not the case. The rubric of column and wall provided a frame of reference, on the other hand, that proved valuable in highlighting fundamental differences. And the suggestion of a space system unique to each and expressed by volume movements in part is compelling as a way forward in a larger effort to understand elements and devices at work in the processes of architectural design.

Would further comparison of different projects by the two reveal more or subtler characteristics? If this parallel of Kahn with Eisenman was continued, what might be revealed in comparing Kahn's First Unitarian Church and School in Rochester with Eisenman's Church of the Year 2000 in Rome? Or if the former's Chemistry Department building at the University of Virginia was substituted for De Vore and the latter's Aronoff Center for Design and Art in Cincinnati for House II, which are the arguments that develop? The plans of these latter two might suffice to make an initial point and suggest the value of the exercise: conventional (traditional) plan organization of plaided field and courtyard and traditional background/figure relations are in the one, much the same disposition distorted and elongated into a series of ribbon-like forms in the other.

What is clear, finally, is that De Vore House and House II render a kind of instability that may characterize modernist architecture. They maintain a resistance to simple interpretation, bearing along a strong trail of ambiguities. And therein, perhaps, it lays the power of their forms and ideas and the on-going ability of the plans after some fifty years to still provoke.

\section{References}

[1] L.I. Kahn, Two houses, Perspecta 3 (1955) 60-61.

[2] R. Giurgol, J. Mehta, Louis I. Kahn, Westview Press, Boulder, Colorado, 1975.

[3] H. Ronner, S. Jhaveri, Louis I. Kahn: Complete Works 1935-1974, Birkhauser, Basel, 1987.

[4] D. Brownlee, D. de Long, Louis I. Kahn: In the Realm of Architecture, Museum of Contemporary Art, Los Angeles, 1991, pp. 72-78.

[5] P. Eisenman, Ten Canonical Buildings, Rizzoli, New York, 2002.

[6] P. Eisenman, Cardboard Architecture: House II, Five Architects: Eisenman, Graves, Gwathmey, Hejduk, Meier, Museum of Modern Art, Wittenborn, New York, 1972, pp. 
9-31.

[7] P. Eisenman, Cardboard architecture, Casabella 37 (374) (1973) 17-31.

[8] P. Eisenman, Houses of Cards, Oxford University Press, Oxford, 1987, pp. 56-59.
[9] P. Ciorra, P. Eisenman: Opere e progetti, Electa, Milano, 1993.

[10] C. Rowe, Neo-“classicism” and modern architecture II, Oppositions 1 (1973) 14-26.

[11] P. Smithson, The space between, Oppositions 4 (1974) 76-78. 